\title{
Arthroscopic Surgery and Radiosynovectomy to the Hip Joint with Diffuse Pigmented Villonodular Synovitis
}

Hasan Ikbal Atilgan, Murat Sadic ${ }^{\star}$, Hakan Ozsoy, Gokhan Koca and Meliha Korkmaz

Department of Nuclear Medicine, Ministry of Health, Ankara Training and Research Hospital, Ankara, Turkey

*Corresponding author: Murat Sadic, M.D, Department of Nuclear Medicine, Ministry of Health, Ankara Training and Research Hospital, Ankara, Turkey, Tel: +90 312 59536 08; Fax: +90 31259538 56; E-mail: mdmuratsadic@gmail.com

Received date: Aug 21, 2015, Accepted date: Aug 31, 2015, Publication date: Sep 04, 2015

Copyright: (C) 2015 Atilgan HI, et al. This is an open-access article distributed under the terms of the Creative Commons Attribution License; which permits unrestricted use; distribution; and reproduction in any medium; provided the original author and source are credited.

\begin{abstract}
A 32-year-old female patient admitted with right hip pain that was diagnosed of diffuse PVNS in right hip joint with magnetic resonance imaging. She went arthoscopic synovectomy for this lesion. Six weeks after the surgery, RS was applied. Before RS three phase bone scintigraphy was taken and minimal increased perfusion, minimal hyperemias were detected in right hip joint. On the late phase images relatively increased activity accumulation in right hip joint was seen. $3 \mathrm{mCi}(111 \mathrm{MBq})$ yttrium-90 colloid was administered to the hip joint under fluoroscopy guidance. The Bremsstrahlung imaging was performed using a gamma camera equiped four hours after RS. In the six and nine months control after RS patient did not have any complaints. In nine months control, MRI and three phase bone scintigraphy were taken and no pathologic radioactivity accumulation on bone scan, any residual lesion or recurrence on MRI was present. To our best knowledge, this is the first case with arthroscopic surgery and adjuvant RS with Y-90 colloid which rarely applied in routine practice for treatment of diffuse PVNS of the hip.
\end{abstract}

Keywords: Radiosynovectomy; Y-90; DPVNS

\section{Introduction}

Pigmented villonodular synovitis (PVNS) is characterized by proliferation of synovial tissue in the joint, tendon sheath and bursa [1]. It occurs most often in middle-aged women and most frequently involves the knee, followed by the hip and ankle [2]. Although trauma, inflammation, neoplasia, hemorrhagic effusion and lipid metabolism disorders have been thought as causative factors, the etiology remains unclear [3]. Pigmented villonodular synovitis have severe symptoms such as joint pain, swelling, hemorrhagic effusion, erythema and limitation in range of motion [4]. The surgical treatment for PVNS is the removal of affected synovial tissue by open or arthroscopic synovectomy [5]. Two forms described for PVNS; noduler and agressive form. Nodular, non-agressive form can be succesfully treated with arthoscopic synovectomy, but much more difficult surgical and oncological challenge should be applied for the aggressive diffuse PVNS [6]. Recurrence is high and recurrent tumours are more destructive and more invasive [7]. Despite extensive surgical approaches, radiosynovectomy (RS) improves local control [8]. To our best knowledge there are no papers presenting the radiosynovectomy to the hip joint with diffuse PVNS after arthroscopic surgery.

\section{Case Report}

A 32-year-old female patient admitted with right hip pain. Magnetic resonance imaging (MRI) with contrast media revealed effusion and synovial hypertrophy compatible with possible diagnosis of diffuse PVNS in right hip joint. She went arthoscopic synovectomy for this lesion. Six weeks after the surgery, RS was applied. Before RS three phase bone scintigraphy was taken and minimal increased perfusion in perfusion phase (Figure 1a), minimal hyperemia in blood pool phase (Figure 1b) were detected in right hip joint. On the late phase images relatively increased activity accumulation in right hip joint was seen (Figure 1c). She was given $3 \mathrm{mCi}(111 \mathrm{MBq})$ yttrium-90 (Y-90) colloid (CIS Bio International, France) to the hip joint under fluoroscopy guidance. We took images for the distribution of Y-90 colloid. The Bremsstrahlung imaging was performed using a gamma camera equiped with a low energy general purpose collimator (Siemens, ECAM, Hoffman Estates, IL, USA) four hours after RS. The retention of Y-90 colloid was normal in hip joint and there was not extraarticular leakage (Figure 2). Following RS, the hip was stabilized for 72 hours. In the six and nine months control after RS patient did not have any complaints. In nine months control, MRI and three phase bone scintigraphy were taken and no pathologic radioactivity accumulation on bone scan, any residual lesion or recurrence on MRI was present.

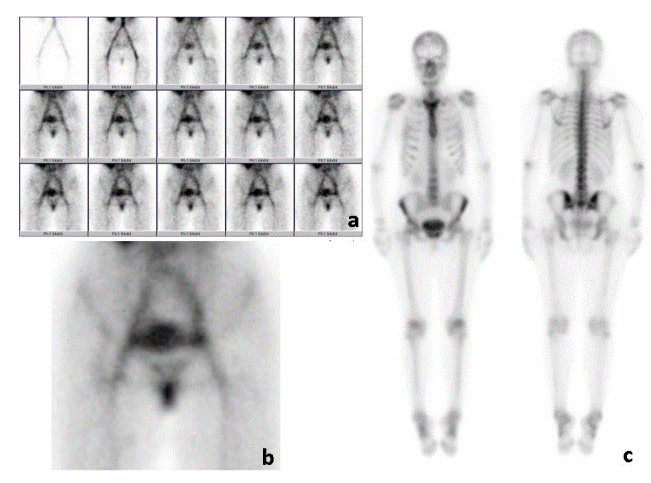

Figure 1: Initial three phase bone scintigraphy. Minimal increased perfusion in perfusion phase. a: minimal hyperemia in blood pool phase, b: relatively increased activity and c: accumulation in right hip joint in late whole body images. 
Citation: Atilgan HI, Sadic M, Ozsoy H, Koca G, Korkmaz M (2015) Arthroscopic Surgery and Radiosynovectomy to the Hip Joint with Diffuse Pigmented Villonodular Synovitis. J Nucl Med Radiat Ther S8: S8-005. doi:10.4172/2155-9619.1000S8-005

Page 2 of 2

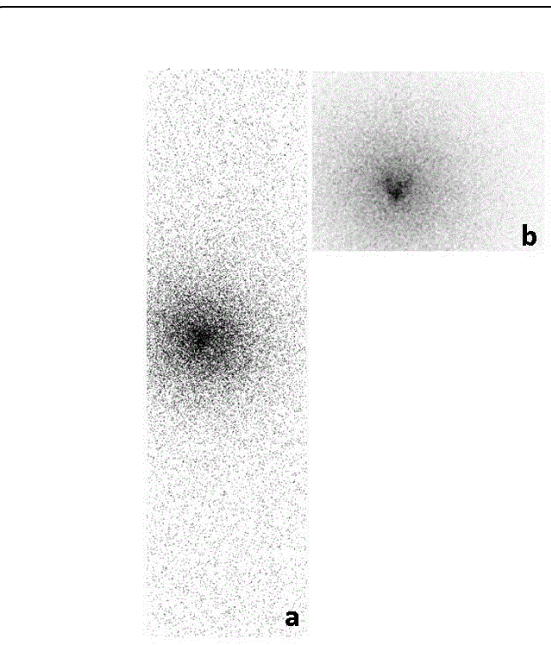

Figure 2: Four hours after Y-90 colloid injection into the right hip joint, anterior whole body. a: and static, b: images show good intraarticular distribution. There was not extraarticular leakage of Y-90 colloid.

\section{Discussion}

Usually only one joint is affected in diffuse PVNS and the most involved joint is knee, followed by hip [9]. The hip is affected in approximately $15 \%$ of cases [10]. Local control is achieved by excision of the localized mass in the localized form, but in diffuse form complete tumor removal is more difficult [11]. Recurrence rate after the treatment of diffuse PVNS may be as much as 46\% [6]. Synovectomy can be applied as arthroscopic surgery or open surgery. Early diagnosis of hip joint involvement is important because femoral head and acetabulum destruction occur. In cases of significant joint arthrosis, synovectomy is combined with arthroplasty [12]. Radiosynovectomy or radiotherapy is recommended after the surgery to prevent the recurrences in the current treatment approaches.

Radiosynovectomy is low cost, effective and easy to perform with few side effects which are generally avoidable [13]. Radiosynovectomy is applied after synovectomy to prevent the recurrences, but there are a few cases that RS was applied after open synovectomy, and there is not any case after arthroscopic surgery of the hip joint. Shabat et al. used Y-90 for diffuse PVNS of hip in one patient after open surgery and achieved the stabilization of disease with no futher joint damage [14]. Zook et al. used P-32 in one patient after two times arthroscopic synovectomy. Two months after radiosynovectomy recurrence was seen [15]. Due to its longer half life and high lymphatic transport P-32 is not recommended [16].

To our best knowledge, this is the first case with arthroscopic surgery and adjuvant RS with Y-90 colloid for treatment of diffuse PVNS of the hip. In our case, we applied arthroscopic surgery and adjuvant RS combination with Y-90 colloid which rarely applied in routine practice for treatment of diffuse PVNS of the hip. Patient did not have any symptoms about her right hip in six and nine month's control. In nine months control, there was not any residual lesion or recurrence on MRI, not any side effects during this follow-up period.

\section{References}

1. Ottaviani S, Ayral X, Dougados M, Gossec L (2011) Pigmented villonodular synovitis: a retrospective single-center study of 122 cases and review of the literature. Semin Arthritis Rheum 40: 539-546.

2. Ma X, Shi G, Xia C, Liu H, He J, et al. (2013) Pigmented villonodular synovitis: a retrospective study of seventy five cases (eighty one joints). Int Orthop 37: 1165-1170.

3. Ma X, Xia C, Wang L, Zhao L, Liu H, et al. (2011) An unusual case of pigmented villonodular synovitis 14 years after total hip arthroplasty. J Arthroplasty 26: 339.

4. Horoschak M, Tran PT, Bachireddy P, West RB, Mohler D, et al. (2009) External beam radiation therapy enhances local control in pigmented villonodular synovitis. Int J Radiat Oncol Biol Phys 75: 183-187.

5. Berger B, Ganswindt U, Bamberg M, Hehr T (2007) External beam radiotherapy as postoperative treatment of diffuse pigmented villonodular synovitis. Int J Radiat Oncol Biol Phys 67: 1130-1134.

6. Koca G, Ozsoy H, Atilgan HI, Demirel K, Dincel VE, et al. (2012) Application of rhenium-186 radiosynovectomy in elbow diffuse pigmented villonodular synovitis. - a case report with multiple joint involvement. Nucl Med Mol Imaging 46: 215-217.

7. Sharma H, Jane MJ, Reid R (2005) Pigmented villonodular synovitis: Diagnostic pitfalls and management strategy. Current Orthopaedics 19: 215-222.

8. Koca G, Ozsoy H, Atilgan HI, Ozyurt S, Demirel K, et al. (2013) A low recurrence rate is possible with a combination of surgery and radiosynovectomy for diffuse pigmented villonodular synovitis of the knee. Clin Nucl Med 38: 608-615.

9. Chen WM, Wu PK, Liu CL (2012) Simultaneous anterior and posterior synovectomies for treating diffuse pigmented villonodular synovitis. Clin Orthop Relat Res 470: 1755-1762.

10. Li LM, Jeffery J (2011) Exceptionally aggressive pigmented villonodular synovitis of the hip unresponsive to radiotherapy. J Bone Joint Surg Br 93: 995-997.

11. Park G, Kim YS, Kim JH, Lee SW, Song SY, et al. (2012) Low-dose external beam radiotherapy as a postoperative treatment for patients with diffuse pigmented villonodular synovitis of the knee: 4 recurrences in 23 patients followed for mean 9 years. Acta Orthop 83: 256-260.

12. Park KS, Diwanji SR, Yang HK, Yoon TR, Seon JK (2010) Pigmented villonodular synovitis of the hip presenting as a buttock mass treated by total hip arthroplasty. J Arthroplasty 25: 333.

13. Wiss DA (1982) Recurrent villonodular synovitis of the knee. Successful treatment with yttrium-90. Clin Orthop Relat Res : 139-144.

14. Shabat S, Kollender Y, Merimsky O, Isakov J, Flusser G, et al. (2002) The use of surgery and yttrium 90 in the management of extensive and diffuse pigmented villonodular synovitis of large joints. Rheumatology (Oxford) 41: 1113-1118.

15. Zook JE, Wurtz DL, Cummings JE, Cárdenes HR (2011) Intra-articular chromic phosphate $\left({ }^{32} \mathrm{P}\right)$ in the treatment of diffuse pigmented villonodular synovitis. Brachytherapy 10: 190-194.

16. Turkmen C (2009) Safety of Radiosynovectomy in Hemophilic Synovitis: it is Time to Re-evaluate! J Coagul Disord 1: 29-36.
This article was originally published in a special issue, entitled: "Medical Radiation Techniques", Edited by Aruna Turaka, Fox Chase Cancer Center, USA 